\title{
Critical Review on Evaporative Loss of Semivolatile Aerosols during Sampling
}

\author{
Seung Won Kim ${ }^{\dagger}$ \\ University of Minnesota, Minneapolis, MN, USA \\ (Received March 10, 2010/Revised April 10, 2010/Accepted May 11, 2010)
}

\begin{abstract}
Semivolatile aerosols exist as vapor and particles at the same time in room temperature and each phase has different intake and uptake mechanisms. This characteristic requires substantial consideration during exposure assessment of semivolatile aerosol. Some sampling methods for solid particles pose high possibility of evaporative loss during sampling. Therefore, when establishing sampling strategy for them, the factors affecting the phase distribution of semivolatile aerosol should be counted including semivolatile aerosol of interest and sampling methods used. Evaluation for phase distributions of semivolatile aerosols is also recommended. Metalworking fluids, pesticides, asphalt fumes, diesel exhaust, and environmental tobacco smoke are common health-related semivolatile aerosols in workplaces.
\end{abstract}

Keywords: semivolatile aerosol, semivolatile organic compound, evaporative loss, vapor phase, particle phase

\section{Introduction}

Semivolatile organic compounds (SVOCs) are substances which have a relatively low vapor pressure, often ranging between $10^{-4}$ and $10^{-11}$ atm. ${ }^{1)}$ In the environmental health science field, chemicals consisting of semivolatile aerosol are collectively called SVOCs. Thus, at room temperature they do not evaporate readily, unlike volatile organic compounds (VOCs). Examples of common semivolatile aerosols include metalworking fluids (MWFs) mist, pesticides, dioxins, diesel exhaust, polycyclic aromatic hydrocarbons (PAHs), asphalt fumes, polychlorinated biphenyls (PCBs), and environmental tobacco smoke (ETS). ${ }^{2-9)}$

Due to their low volatility, some semivolatile aerosols have been recommended to be evaluated using particle sampling devices. Depending on the principles of particle collection, however, some sampling devices carry great potential of evaporative loss during sampling.

Corresponding author : University of Minnesota, Minneapolis, MN, USA

Tel: 1-612-418-2314, Fax: 1-304-285-6041

E-mail: kim.seungwon@gmail.com
Due to multi-phase characteristics, more systemic approaches are required to evaluate semivolatile aerosol exposures including evaporative losses during sampling. Industrial hygienists should not only be aware of the factors affecting the equilibrium of SVOCs between the vapor and particle phases, but also be cognizant of the strengths and limitations of airborne SVOC concentration measuring techniques and their phase distributions.

This article summarizes the results of extensive literature review on aerosol and vapor sampling methods and health-related semivolatile aerosols commonly recognized in workplaces for referencing in semivolatile aerosol sampling.

\section{Semivolatile Aerosol Sampling Methods}

Several different sampling device technologies are available to evaluate semivolatile aerosols concentrations. Devices sampling only one phase are not always appropriate for measuring semivolatile aerosols due to the characteristics of SVOCs described previously. Depending on the principles of the sampling mechanism, some 
Table 1. Summary of semivolatile aerosol sampling methods

\begin{tabular}{|c|c|c|c|}
\hline Sampling method & Example & Advantages & Limitations \\
\hline \multicolumn{4}{|l|}{ Particle phase } \\
\hline Filtration & MWFs by Volckens et al. ${ }^{11)}$ & $\begin{array}{l}\text { Low sampling cost and simple } \\
\text { setup }\end{array}$ & Evaporative loss during sampling \\
\hline $\begin{array}{l}\text { Electrostatic } \\
\text { precipitators }\end{array}$ & MWFs by Leith et al. ${ }^{12)}$ & $\begin{array}{l}\text { Less evaporative loss and low } \\
\text { cutsize }\end{array}$ & $\begin{array}{l}\text { Extra weight for power supply } \\
\text { and possibility of chemical } \\
\text { artifacts }\end{array}$ \\
\hline Impactors & MWFs by Woskie et al. ${ }^{6}$ & Information on size distributions & Evaporative loss during sampling \\
\hline Virtual impactors & $\begin{array}{l}\text { MWFs by Kim and } \\
\text { Raynor }^{13)}\end{array}$ & $\begin{array}{l}\text { No evaporative loss and } \\
\text { information on phase distributions }\end{array}$ & Not tested for personal sampling \\
\hline \multicolumn{4}{|l|}{ Vapor phase } \\
\hline Sorbent tubes & $\begin{array}{l}\text { MWFs by Kim and } \\
\text { Raynor }^{13)}\end{array}$ & No evaporative loss & $\begin{array}{l}\text { Low collection rate and } \\
\text { difficulties in analysis }\end{array}$ \\
\hline Diffusive samplers & $\begin{array}{l}\text { MWFs by Simpson and } \\
\text { Wright }^{14)}\end{array}$ & $\begin{array}{l}\text { Minimal burden for sampler } \\
\text { wearers }\end{array}$ & $\begin{array}{l}\text { Recommended for high } \\
\text { concentrations }\end{array}$ \\
\hline Diffusion denuders & $\begin{array}{l}\text { Toluene diisocyanate by } \\
\text { Nordqvist }^{15)}\end{array}$ & $\begin{array}{l}\text { Low detection limit and } \\
\text { information on phase distributions }\end{array}$ & Commercially not available \\
\hline Cold traps & $\begin{array}{l}\text { Volatile aerosol by } \\
\text { Soderholm }\end{array}$ & $\begin{array}{l}\text { Applicable for vapor and } \\
\text { aerosols }\end{array}$ & Tested only in laboratory settings \\
\hline
\end{tabular}

methods are more prone to evaporative losses than others. For particle sampling, the cutsize of sampling devices is highly important. Cutsize, also referred to as cutpoint or cutoff size, is the hypothetical aerodynamic particle diameter for which all particles greater than this diameter are collected and all particles less than this diameter are not collected and pass through in a particulate sampling device. ${ }^{10)}$ The real cutsize differs from hypothetical diameter partly because particles are never perfect spheres and generally have different densities. As such, there is always an imperfect efficiency curve rather than the idealistic and physically impossible step function. Another important factor to be considered is portability of sampling instruments, which is critical in the industrial hygiene field where personal exposure assessment are more meaningful.

Table 1 presents the summary of available sampling methods for each phase of semivolatile aerosols, their advantages and limitations, and example studies adopted each method.

\section{Particle Phase Measurement Methods}

1) Filtration

Filters are designed to have large effective surface areas and can remove particles when air passes through them. The mechanisms of filtration are impaction, interception, diffusion, electrical attraction, and sedimentation. ${ }^{17}$ ) The collection efficiency of a given filter media varies with the face velocity and particle size. Accurate assessment of semivolatile aerosols using filtration methods only is not possible due to the large evaporative losses associated with filters, their large effective surface areas, and particles in an airstream.

Currently standard methods for measuring some SVOC concentrations depend primarily on sampling using a variety of different filter media. Table 2 shows the United States National Institute for Occupational Safety and Health (US NIOSH) sampling methods for some mixed SVOCs. ${ }^{19)}$ Sampling methods using filter media only (5026, $5524,5042,0600$, and 5005) can collect some of the SVOCs present, but they each demonstrate significant evaporative losses for the particles captured on filter media. In other words, for the amount of SVOC particles captured and available for subsequent analysis, the amount lost is significant. In the case of metalworking fluid mist, Volckens et al. ${ }^{11)}$ showed that concentrations determined that sampling with filters resulted in 
Table 2. US NIOSH sampling methods for mixed semivolatile organic compounds

\begin{tabular}{|c|c|c|c|}
\hline \multicolumn{2}{|c|}{ Semivolatile organic compounds } & US NIOSH sampling method & Possibility of evaporative loss \\
\hline \multirow{2}{*}{\multicolumn{2}{|c|}{ MWFs }} & \# 5026 & $\mathrm{O}$ \\
\hline & & \# 5524 & $\mathrm{O}$ \\
\hline & Asphalt fume & $\# 5042$ & $\mathrm{O}$ \\
\hline \multirow{3}{*}{$\mathrm{ETS}^{\mathrm{a}}$} & Respirable particulate fraction & \# 0600 & $\Delta$ \\
\hline & Nicotine & \# 2544 & $x$ \\
\hline & & \# 2551 & $\times$ \\
\hline \multirow{6}{*}{ Pesticides } & Organophosphorus & $\# 5600$ & $x$ \\
\hline & Organonitrogen & \# 5601 & $x$ \\
\hline & Chlorinated Organonitrogen & $\# 5602$ & $\times$ \\
\hline & Aldrin & \# 5502 & $\Delta$ \\
\hline & Thiram & \# 5005 & $\Delta$ \\
\hline & Temephos & PV $2056^{\mathrm{b}}$ & $\Delta$ \\
\hline
\end{tabular}

O: significant, $\Delta$ : possible, $\times$ : not likely

${ }^{a}$ Environmental Tobacco Smoke (ETS) itself is not a substance regulated by US Occupational Safety and Health Administration (OSHA).

${ }^{b}$ US OSHA method ${ }^{18)}$.

underestimating the true value of the concentrations by $75-80 \%$. In the case of ETS respirable particulate fraction sampling using US NIOSH method 0600 , the possibility of evaporative loss is highly dependent on the sampling situation. For example, samples taken near smokers experience more evaporation than samples taken far from smokers. This makes intuitive sense since volatile materials are known to evaporate from particles within short time periods (seconds to minutes) after ETS is emitted into the air. ${ }^{20)}$ Other US NIOSH methods specify the use of different sampling technology other than filtration method. For nicotine, organophosphorus pesticides, organonitrogen pesticides, and chlorinated organonitrogen pesticides, the methods listed in Table 2 use only sorbent tubes. As they specify the use of sorbent tubes downstream of the filters and thus do not have the typical problems of underestimation due to evaporation. While this is beneficial in accurately determining the total airborne concentrations of SVOCs, this method cannot differentiate among the expected different SVOC phases.

Adding to the challenge of accurately measuring, interaction between SVOC and filter media is another influencing factor. Specifically, there is a great probability that the vapor molecules of interest can be adsorbed on the filter media or adsorbed on the accumulated particulate and organic matter residing on the surface of the filter media. ${ }^{21)}$ This artifact results in an misleading increase in the particle phase loading of the SVOCs in question.

2) Electrostatic precipitators (ESPs)

As an alternative method of sampling, ESPs have long been used to electrically charge particles and collect them for later measurement by attracting and sticking them to the surface with opposite polarity. ESPs have the ability to collect very small particles down to the nanometer range. ${ }^{22)}$ Tolman et al. ${ }^{23)}$ was able to collect smoke particles by employing electrostatic precipitation in 1910's. Today, ESPs are used to collect samples of general aerosols, bioaerosols, and radioactive aerosols. ${ }^{24-27)}$ More commonly, ESPs are now used to collect samples for analysis by microscopy. ${ }^{28)}$ Leith et al. ${ }^{12)}$ developed a portable ESP for personal sampling and compared measured oil mist concentrations from the ESP versus filters. They found that an ESP had several times less loss of sampled mass during an air flow test than filters did. However, the evaporative loss problem remained. Another concern regarding ESP accuracy is that semivolatile 
aerosols collected on ESPs are susceptible to reactions and degradation due to ozone generated by corona. ${ }^{29-31)}$ By nature of the ESP design, these instruments unfortunately generate amounts of ozone that can affect the accuracy of the measurement results. Further, these high-power, high-voltage instruments are relatively heavy and bulky raising ergonomic concerns for the workers that wear these personal sampling devices. Worker safety (shock/ electrocution) and fire hazard concerns due to the high voltage can place limits on the use of ESPs in some work environments. ESPs can be ignition sources. As such, industrial hygienists should never have workers wear portable ESPs in explosive environments no matter how ergonomicallyimproved the instrument may be.

\section{3) Impactors}

Inertial impactors are common instruments and have been used extensively for collecting airborne particles. They are relatively inexpensive and are often portable. Inertial impactors entered the scientific community in the 1860 's. ${ }^{32)}$ Currently, impactors usually have multiple stages, each containing a particle collection plate. The impactor is essentially a series of chambers designed to create different aerodynamic microenvironments for the purpose of using these different microenvironments along with particle inertia (different masses and accelerations) and sorting out and collection particles on the chambers' collection plates. The characteristics of impactors and the fluid flow in them have been thoroughly studied. ${ }^{33-36)}$ Unfortunately, evaporative losses also occur with impactors because of the air flow through the chambers and the heightened aerosol speeds within each chamber. Increased air speeds around the collection plates exacerbate the evaporation problems previously mentioned. ${ }^{37}$

4) Virtual impactors

A virtual impactor does not have collection plates. Instead, the instrument employs a collection probe beneath an impactor jet. In the jet large particles are focused to the center of the minor flow passing to the collection probe and are depleted in the main flow. Virtual impactors separate particles from air instantly and keep them airborne. Most virtual impactors currently available are large and require such a high airflow rate, 1.7 $\mathrm{m}^{3} / \mathrm{hr}(1 \mathrm{cfm})$ or higher, that they can not be used for personal sampling. They have large internal losses of particles with diameters near the cutoff size. The major advantage of virtual impactors is that they are capable of minimizing errors associated with particle bounce (or re-entrainment) and can concentrate airborne particles for subsequent analysis. One limitation to be aware of is that virtual impactors have significant wall losses for liquid particles near the cutpoint. ${ }^{22)}$

Since the introduction of the round-nozzle virtual impactor in the 1960's, virtual impactor designs have evolved through experimental efforts and theoretical studies. ${ }^{38-43}$ ) Studies of unconventional new designs ensued. For example, slit nozzle virtual impactors were studied by Ravenhall et $a l^{44)}$ and Forney et $a l^{45)}$ and further developed by other interested scholars such as Sioutas et al. ${ }^{46)}$ and Ding and Koutrakis ${ }^{47)}$. With a unique alternative design, Masuda and Nakasita ${ }^{48)}$ investigated a rectangular nozzle jet virtual impactor. Chein and Lundgren $^{49)}$ and Li and Lundgren ${ }^{50)}$ evaluated virtual impactor configurations having a clean air core in the middle of the jet stream to achieve cleaner separation characteristics. Noone et al. ${ }^{51)}$ developed a counterflow virtual impactor as an aircraft-mounted sampling device to collect cloud droplets. In a later development, Boulter et al. ${ }^{52)}$ modified this to be operated without depending on an outside air current.

5) Other particle measurement methods

New categories of instruments were also developed as additional tools to sample particles. Devices such as impingers, cyclone samplers, aerosol centrifuges, elutriators, and thermal precipitators were developed and are available for particle sampling. ${ }^{22)}$ Of these, the cyclone sampler, aerosol centrifuge, elutriator, and thermal precipitator designs are also subject to evaporative losses which contribute to measurement error. For personal exposure assessment, impingers and aerosol centrifuges are generally not suitable due to their portability. As a result of above reasons, these devises seldom have been used for semivolatile aerosol sampling except cyclones. In most cases, cyclones have been used as a preseparator to 
obtain a more specific size fraction of particles such as the thoracic and respirable fraction. ${ }^{53-55)}$

Direct-reading instruments are also available for analyzing airborne particles. However, they currently are of limited use in research since they can only count particles and/or size particles. Since they neither actively analyze nor capture particles for subsequent analysis, in order to determine the composition of the particles, separate methods are required to completely characterize the aerosols of interest.

\section{Vapor Phase Measurement Methods}

\section{1) Sorbent tubes}

Activated carbon is an excellent sorbent for most organic vapors. ${ }^{56)}$ Inside the tube, the air is forced through and the vapor molecules diffuse and are adsorbed onto the carbon. Activated carbon tubes (ACTs) are recommended by US NIOSH for the sampling of airborne vapors with volatile hydrocarbons. However, sorbent tubes can sample particles both on the filter plugs inside the tube as well as on the sorbent media. Cohen et $a l .{ }^{57)}$ found that the air concentrations of xylene sampled by ACTs were higher than those determined by $3 \mathrm{M}$ diffusion monitors at paint spray operations. This finding was attributed to the ACTs capturing not only vapor molecules but also particles.

2) Diffusive samplers

Diffusive samplers take samples of vapor from air by diffusion or permeation through a membrane without the active movement of air. Ambient air velocity and orientation can affect the performance of a diffusive sampler. ${ }^{56)}$ Most diffusive samplers require minimum face velocities in order to take representative samples. Further, certain applications are contra-indicators of good use. For example, in paint spray applications where vapor and particles coexist, airborne droplets containing solvent can damage the membrane of diffusive samplers causing an increase in the sampling rate for the solvent vapor. This can result in significant overestimation of the vapor concentration. ${ }^{57)}$ Recently, Simpson and Wright ${ }^{14)}$ measured mixed $\mathrm{C}_{7}-\mathrm{C}_{16}$ hydrocarbon vapors using diffusive samplers and found that as molecular weight increased, the diffusive uptake rate decreased and the standard uncertainty increased. It was found that a small amount of SVOCs were adsorbed on the internal metal surface of the thermal desorption tube samplers. The authors of this study ultimately recommended not using diffusive samplers when the mist concentration is known to be lower than $3 \mathrm{mg} / \mathrm{m}^{3}$.

\section{3) Diffusion denuders}

A diffusion denuder is a tube or set of tubes through which the atmospheric sample is passed. The inside of the tube is coated with a material which collects the components of interest. Because the diffusion coefficients of particles and vaporphase molecules differ enormously by $10^{3}-10^{6}$, the particles tend to pass through the tube while the vapor phase components tend to diffuse to the wall and accumulate. ${ }^{58)}$ The design of denuders has been changed from glass or metallic hollow tubes into various configurations such as annular tubes, honeycomb matrix, compact coil, a gas chromatographic column bundle, and a compact porous-metal. ${ }^{59-63)}$ The selectivity of coating materials can be a strength or a weakness depending on the application. In mixed SVOCs sampling, this selectivity can bias the measured concentrations because some components of SVOCs may not be captured by a coating. Turpin et al ${ }^{64)}$ developed a diffusion separator that uses clean airflow instead of a coating. However, this device is sensitive to the air temperature and not appropriate for contaminants which normally have low airborne concentrations.

4) Other methods

Cold traps convert gaseous contaminants into liquid or solid forms and have been commonly used for chemical identification purposes. ${ }^{56)}$ When vapor passes though a cooling system, it can then be separated from air stream by condensation. Soderholm ${ }^{16)}$ adopted this method to sample semivolatile aerosols as well as vapor. Sampling bags can also be employed for integrated air sampling. ${ }^{56}$ Personal sampling is also possible with this method. However, particles might deposit on the surface of bags depending on the size of the particle and the sampling time. Direct-reading instruments are also available for evaluating vapor 
concentration. However, in many cases the compounds in the vapor must be known first to use this method. Note also that not all instruments are designed to be compatible in an explosive environment.

\section{Common Semivolatile Aerosols}

\section{Oil mist}

MWF mists pose a potential hazard to more than 1.2 million workers in the United States. ${ }^{19)}$ Epidemiological studies have linked MWF mist exposure to cancer, ${ }^{65)}$ respiratory ailments, ${ }^{66,67)}$ and dermatitis. ${ }^{68,69)}$ Volckens et al. ${ }^{11)}$ reported that the evaporative loss of soluble MWFs during sampling with filters ranged up to $75-80 \%$ of the true concentrations. The mass median aerodynamic diameters (MMADs) and geometric standard deviations (GSDs) for straight oil mists were measured as 3.8-7.7 $\mu \mathrm{m}$ and 2.4-3.4, respectively. For soluble oil mists, they measured 4.2-8.2 $\mu \mathrm{m}$ and $2.2-3.7 .^{70)}$ In another study focused on automotive plants, the overall oil mist mean MMAD and GSD was determined to be $4.9 \mu \mathrm{m}$ and 2.5 , respectively. ${ }^{53)}$ In the study of Kim and Raynor, ${ }^{13)}$ the percentages of vapor phase for two different MWFs aerosol were 50.1\% and 38.9\%, respectively. Some components of MWFs other than base oil, such as alkanolamine, are also volatile or semivolatile. $^{71)}$

\section{Pesticides and dioxins}

Pesticides and herbicides are substances or mixtures of substances used to control pests, weeds and microbes. Workers and bystanders can be exposed to pesticides during production and distribution of pesticides as well as their application. ${ }^{72)}$ The World Health Organization (WHO) estimated that 3 million workers in agriculture in the developing world experience severe poisoning from pesticides each year, about 18,000 of whom die. $^{73)}$ The health effects of pesticide exposure range from headaches to cancer, depending on the type of pesticide and amount of exposure. International Agency for Research on Cancer $(\text { IARC })^{74)}$ listed more than 20 pesticides as probable or possible human carcinogens. Some pesticides include known cancer causing compounds, such as dioxins, as by-products. ${ }^{75)}$

Many semivolatile pesticides can be sampled with OSHA Versatile Sampler (OVS) tubes, although the analyzing methods for each pesticide group or individual pesticide are different. ${ }^{18,76,77)}$ Most organophosphorus pesticides and organonitrogen pesticides sampling can be covered by this sampling media. The structure of OVS tube allows for simultaneous collection of aerosol and vapors. However, that does not mean the phase information of pesticides can be obtained using this method. By adding sorbent material after filter, OVS tubes are not subjective to evaporative loss during sampling. While OSHA requires using glass fiber filter for pre-filtration, NIOSH requires quartz filter. Several pesticides (e.a. aldrin, demeton, temephos, thiram) have recommended methods other than OVS tubes. NIOSH recommends the combination of glass fiber filter and bubbler containing isooctane and the combination of MCE filter and XAD-2 tube for aldrin and demeton sampling, respectively. ${ }^{78,79)}$ The NIOSH method for thiram recommends a PTFE filter and the OSHA method refers to the same NIOSH method for sampling. Even though thiram is a white solid in room temperature, EPA has reported its vapor pressure as $2.2 \times 10^{-8}$ atm at $25^{\circ} \mathrm{C}$ and $\mathrm{ACGIH}$ gives an 'IFV' notation for this substance, which stands for inhalable fraction and vapor. ${ }^{80,81)}$ The OSHA method for temephos requires using a glass fiber filter. Except for the methods for demeton, all other methods have the possibility of evaporative loss of captured substance during sampling.

Dioxins, as a group, are structurally and chemically related polychlorinated dibenzo para dioxins (PCDDs) and polychlorinated dibenzofurans (PCDFs) including dioxin, 2,3,7,8-tetrachlorodibenzo para dioxin (TCDD). Dangerous PCDDs are formed as inadvertent by-products during the production of some herbicides. PCDDs and PCDFs may also be produced in incinerators, thermal metal processing, and paper pulp bleaching with free chlorine. ${ }^{75)}$ Short-term exposure to dioxins can cause skin lesions and altered liver function. Long-term exposure is linked to several types of cancer and impairment of the human immune system, the developing nervous system, the endocrine system, and the reproductive functions. 
TCDD was classified by IARC as a known human carcinogen. $^{82)}$

\section{Diesel exhaust, asphalt fume, and PAHs}

Diesel exhaust is a mixture of particles and gases emitted by internal combustion engines using diesel as fuel. This exhaust is concerning since it contains more than several hundred different organic and inorganic compounds including PAHs. ${ }^{83,84)} \mathrm{WHO}^{85}$ reported elevated levels of lung cancer for railroad workers and truck drivers, occupations typically associated with higher than normal levels of exposure to diesel exhaust. Acute and chronic respiratory diseases including bronchitis and asthma have been reported to be related to diesel emission exposure. ${ }^{84)}$

Asphalt is ubiquitous in the environment. It is a dark, high-boiling point material derived from petroleum refining. Approximately $99 \%$ of asphalt use is in paving and roofing. Paving contractors employ approximately 300,000 workers in the United States. ${ }^{86)}$ About 50,000 roofers are exposed to asphalt fumes in the US Workers exposed to asphalt fumes often suffer from eye, nose, and throat irritation. ${ }^{86)}$ Kitto et al. ${ }^{87)}$ reported the phase distribution of gaseous asphalt and particulate asphalt in various conditions and their size distributions. Hazardous components of asphalt include polycyclic aromatic compounds (PACs) and PAHs. Asphalt fume is one of the semivolatile aerosols have been studied widely. ${ }^{9,88)}$

PAHs are organic compounds that consist of multiple fused aromatic rings. Benzo[a]pyrene is well known for its carcinogenicity and belongs to this group. PAHs are produced from smoking and fuel burning and humans are exposed to them by inhalation. ${ }^{89)}$ Mutagenic and carcinogenic effects, bone marrow toxicity, reproductive toxicity, and immunosuppressive effects have been reported as the potential health effects from PAHs. ${ }^{90-92)}$

\section{Environmental tobacco smoke (ETS)}

ETS, often referred to as secondhand smoke, includes more than 4,000 chemical compounds, many of which are carcinogenic, toxic, or irritating. Nonsmokers can be exposed to ETS in homes, workplaces, and public places. Musicians and employees in bars, nightclubs, and lounges have been exposed to high levels of ETS. ${ }^{93)}$ The health effects from exposure to ETS include developmental disorders, respiratory symptoms, cardiovascular diseases, and cancers. ${ }^{94)}$ Scherer et al ${ }^{95,96)}$ reported that the uptake rates of tobacco smoke compounds in each phase are significantly different and that each phase affects biological intake measures differently.

\section{Conclusions and Recommendations}

Due to their low vapor pressure, semivolatile aerosols have a substantial possibility of evaporative loss during sampling. Factors affecting the degree of evaporation include the semivolatile aerosol of interest, mechanism of aerosol generation, sampling methods used, temperature and humidity, number of semivolatile compounds, and existence of other particles. To evaluate semivolatile aerosol concentrations more accurately, these factors should be considered during the planning and execution of actual sampling. The control strategy should also address the contaminant's semivolatile characteristics. Because the intake and uptake mechanisms of the two phases are different, human exposures and outcomes can vary significantly. Assessing each phase separately is essential in order to fully characterize exposure profiles of semivolatile organic compound in workplaces.

\section{References}

1. Bidleman, T. F. : Atmospheric processes - wet and dry deposition of organic-compounds are controlled by their vapor particle partitioning. Environmental Science \& Technology, 22(4), 361-367, 1988.

2. Hawthorne, S., Miller, D., Louie, P., Butler, R. and Mayer, G. : Vapor-phase and particulate-associated pesticides and PCB concentrations in eastern North Dakota air samples. Journal of Environmental Quality, 25(3), 594-600, 1996.

3. Norseth, T., Waage, J. and Dale, I. : Acute effects and exposure to organic compounds in road maintenance workers exposed to asphalt. American Journal of Industrial Medicine, 20(6), 737-744, 1991.

4. CONCAWE: Health aspects of worker exposure to oil mists. Brussels: Conservation of Clean Air and Water in Europe, 1986.

5. Lioy, P. and Daisey, J. : Airborne toxic elements and organic substances. Environmental Science \& 
Technology, 20(1), 8-14, 1986.

6. Woskie, S., Smith, T., Hammond, S., Schenker, M., Garshick, E. and Speizer, F. : Estimation of the diesel exhaust exposures of railroad workers: I. Current exposures. American Journal of Industrial Medicine, 13(3), 381-394, 1988.

7. Zaebst, D., Clapp, D., Blade, L., Marlow, D., Steenland, K., Hornung, R., Scheutzle, D. and Butler, J. : Quantitative determination of trucking industry workers exposures to diesel exhaust particles. American Industrial Hygiene Association Journal, 52(12), 529-541, 1991.

8. Pankow, J. : A consideration of the role of gas/particle partitioning in the deposition of nicotine and other tobacco smoke compounds in the respiratory tract. Chemical Research in Toxicology, 14(11), 1465-1481, 2001.

9. Kriech, A., Kurek, J., Wissel, H., Osborn, L. and Blackburn, G. : Evaluation of worker exposure to asphalt paving fumes using traditional and nontraditional techniques. American Industrial Hygiene Association Journal, 63(5), 628-635, 2002.

10. Hinds, W. : Aerosol Technology: Properties, Behavior, and Measurement of Airborne Particles. Wiley-Interscience, New York, 1999.

11. Volckens, J., Boundy, M., Leith, D. and Hands, D. : Oil mist concentration: a comparison of sampling methods. American Industrial Hygiene Association Journal, 60(5), 684-689, 1999.

12. Leith, D., Leith, F. and Boundy, M. : Laboratory measurements of oil mist concentrations using filters and an electrostatic precipitator. American Industrial Hygiene Association Journal, 57(12), 1137-1141, 1996.

13. Kim, S. W. and Raynor, P. C. : Experimental evaluation of oil mists using a semivolatile aerosol dichotomous sampler. Journal of Occupational and Environmental Hygiene, 7(4), 203-215, 2010.

14. Simpson, A. and Wright, M. : Diffusive sampling of C7-C16 hydrocarbons in workplace air: uptake rates, wall effects and use in oil mist measurements. Annals of Occupational Hygiene, 52(4), 249-257, 2008.

15. Nordqvist, Y., Nilsson, U. and Colmsjö, A. : Investigation of a cylindrical chemosorptive denuder for sampling and phase separation of toluene diisocyanate aerosols. Analytical and Bioanalytical Chemistry, 382(5), 1294-1299, 2005.

16. Soderholm, S. : Method of measuring the total deposition efficiency of volatile aerosols in humans. Journal of Aerosol Science, 22(7), 917-926, 1991.

17. Lippmann, M. : Filters and filter holders. In Air Sampling Instruments for Evaluation of Atmospheric Contaminants, B.S. Cohen and C.S.J. McCammon (eds.), pp.281-284. Cincinnati: American Conference of Governmental Industrial Hygienists, 2001.

18. US OSHA : Sampling and Analytical Methods.
[Online] Available at http://www.osha.gov/dts/sltc/ methods/index.html, Accessed on December 1, 2009.

19. US NIOSH : Occupational Exposure to Metalworking Fluids. United States National Institute of Occupational Safety and Health, 1998.

20. NRC: Environmental tobacco smoke - measuring exposures and assessing health effects. International Agency for Research on Cancer, 1986.

21. Peters, A., Lane, D., Gundel, L., Northcott, G. and Jones, K. : A comparison of high volume and diffusion denuder samplers for measuring semivolatile organic compounds in the atmosphere. Environmental Science \& Technology, 34(23), 5001-5006, 2000.

22. Hering, S. : Impactors, cyclones, and other particle collectors. In Air Sampling Instruments for Evaluation of Atmospheric Contaminants, B.S. Cohen and C.S.J. McCammon (eds.), pp.315-354. Cincinnati: American Conference of Governmental Industrial Hygienists, 2001.

23. Tolman, R., Reyerson, L., Brooks, A. and Smyth, H. : An electrical precipitator for analyzing smokes. Journal of the American Chemical Society, 41(4), 587-589, 1919.

24. Bergstedt, B. : Application of the electrostatic precipitator to the measurement of radioactive aerosols. Journal of Scientific Instruments, 33, 142-148, 1956.

25. Wilkening, M. : A monitor for natural atmospheric radioactivity. Nucleonics, 10(6), 36-39, 1962.

26. Decker, H., Buchanan, L., Frisque, D., Filler, M. and Dahlgren, C. : Advances in large-volume air sampling. Contamination Control, 8, 13-17, 1969.

27. Mainelis, G., Adhikari, A., Willeke, K., Lee, S., Reponen, T. and Grinshpun, S. : Collection of airborne microorganisms by a new electrostatic precipitator. Journal of Aerosol Science, 33(10), 1417$1432,2002$.

28. Dixkens, J. and Fissan, H. : Development of an electrostatic precipitator for off-line particle analysis. Aerosol Science and Technology, 30(5), 438453, 1999.

29. Kaupp, H. and Umlauf, G. : Atmospheric gas-particle partitioning of organic compounds: comparison of sampling methods. Atmospheric Environment, 26(13), 2259-2267, 1992.

30. Cardello, N., Volckens, J., Tolocka, M. P., Wiener, R. and Buckley, T. J. : Technical note: Performance of a personal electrostatic precipitator particle sampler. Aerosol Science and Technology, 36(2), 162165, 2002.

31. Volckens, J. and Leith, D. : Electrostatic sampler for semivolatile aerosols: Chemical artifacts. Environmental Science \& Technology, 36(21), 46084612, 2002.

32. Marple, V. : History of Impactors-The First 110 Years. Aerosol Science and Technology, 38(3), 247- 
292, 2004.

33. Fuchs, N. : The Mechanics of Aerosols. New York: Pergamon Press, 1964.

34. Marple, V. : Fundamental Study of Inertial Impactors: COO--1248-21, Minnesota Univ., Minneapolis. Particle Technology Lab., 1970.

35. Marple, V. and Liu, B. : Characteristics of laminar jet impactors. Environmental Science and Technology, 8(7), 648-654, 1974.

36. Marple, V. and Liu, B. : On fluid flow and aerosol impaction in inertial impactors. Journal of Colloid and Interface Science, 53, 31-34, 1975.

37. Zhang, X. and McMurry, P. : Theoretical analysis of evaporative losses from impactor and filter deposits. Atmospheric Environment, 21(8), 17791789, 1987.

38. Hounam, R. and Sherwood, R. : The cascade centripeter: a device for determining the concentration and size distribution of aerosols. American Industrial Hygiene Association Journal, 26(2), 122-131, 1965.

39. Conner, W. : An inertial-type particle separator for collecting large samples. Journal of the Air Pollution Control Association, 16(1), 35-38, 1966.

40. Dzubay, T. and Stevens, R. : Ambient air analysis with dichotomous sampler and $\mathrm{x}$-ray fluorescence spectrometer. Environmental Science \& Technology, 9(7), 663-668, 1975.

41. McFarland, A., Ortiz, C. and Bertch Jr, R. : Particle collection characteristics of a single-stage dichotomous sampler. Environmental Science \& Technology, 12(6), 679-682, 1978.

42. Marple, V. and Chien, C. : Virtual impactors: a theoretical study. Environmental Science \& Technology, 14(8), 976-985, 1980.

43. Loo, B. and Cork, C. : Development of high efficiency virtual impactors. Aerosol Science and Technology, 9(3), 167-176, 1988.

44. Ravenhall, D., Forney, L. and Jazayeri, M. : Aerosol sizing with a slotted virtual impactor. Journal of Colloid and Interface Science, 1, 108-117, 1978.

45. Forney, L., Ravenhall, D. and Lee, S. : Experimental and theoretical study of a two-dimensional virtual impactor. Environmental Science \& Technology, 16(8), 492-497, 1982.

46. Sioutas, C., Koutrakis, P. and Burton, R. : A highvolume small cutpoint virtual impactor for separation of atmospheric particulate from gaseous pollutants. Particulate Science and Technology, 12(3), 207-221, 1994.

47. Ding, Y. and Koutrakis, P. : Development of a dichotomous slit nozzle virtual impactor. Journal of Aerosol Science, 31(12), 1421-1431, 2000.

48. Masuda, H. and Nakasita, S. : Classification performance of a rectangular jet virtual impactor. Effect of nozzle width ratio of collection nozzle to acceleration jet. Journal of Aerosol Science, 19(2), 243-252, 1988
49. Chein, H. M. and Lundgren, D. A. : A virtual impactor with clean-air core for the generation of aerosols with narrow size distributions. Aerosol Science and Technology, 18(4), 376-388, 1993.

50. Li, S. and Lundgren, D. : Effect of clean air core geometry on fine particle contamination and calibration of a virtual impactor. Aerosol Science and Technology, 27(5), 625-635, 1997.

51. Noone, K., Ogren, J., Heintzenberg, J., Charlson, R. and Covert, D. : Design and calibration of a counterflow virtual impactor for sampling of atmospheric fog and cloud droplets. Aerosol Science and Technology, 8(3), 235-244, 1988.

52. Boulter, J. E., Cziczo, D. J., Middlebrook, A. M., Thomson, D. S. and Murphy, D. M. : Design and performance of a pumped counterflow virtual impactor. Aerosol Science and Technology, 40(11), 969-976, 2006.

53. Piacitelli, G., Sieber, W., O Brien, D., Hughes, R., Glaser, R. and Catalano, J. : Metalworking fluid exposures in small machine shops: an overview. American Industrial Hygiene Association Journal, 62(3), 356-370, 2001.

54. O Brien, D., Piacitelli, G., Sieber, W., Hughes, R. and Catalano, J. : An evaluation of short-term exposures to metalworking fluids in small machine shops. American Industrial Hygiene Association Journal, 62(3), 342-348, 2001.

55. Verma, D., Shaw, D., Shaw, M., Julian, J., McCollin, S. and des Tombe, K. : An evaluation of analytical methods, air sampling techniques, and airborne occupational exposure of metalworking fluids. Journal of Occupational and Environmental Hygiene, 3(2), 53-66, 2006.

56. Brown, R. and Monteith, L. : Gas and vapor sample collectors. In Air Sampling Instruments for Evaluation of Atmospheric Contaminants, B. Cohen and C.S.J. McCammon (eds.), pp. 421-424. Cincinnati: American Conference of Governmental Industrial Hygienist, 2001.

57. Cohen, B., Brosseau, L., Fang, C., Bower, A. and Snyhder, C. : Measurement of air concentrations of volatile aerosols in paint spray applications. Applied Occupational and Environmental Hygiene, 7, 514-521, 1992.

58. Krieger, M. and Hites, R. : Diffusion denuder for the collection of semivolatile organic compounds. Environmental Science \& Technology, 26(8), 1551$1555,1992$.

59. Durham, J., Wilson, W. and Bailey, E. : Application of an $\mathrm{SO}_{2}$-denuder for continuous measurement of sulfur in submicrometric aerosols. Atmospheric Environment, 12(4), 883-886, 1978.

60. Possanzini, M., Febo, A. and Liberti, A. : New design of a high-performance denuder for the sampling of atmospheric pollutants. Atmospheric Environment, 17(12), 2605-2610, 1983.

61. Gunderson, E. and Anderson, C. : Collection device 
for separating airborne vapor and particulates. American Industrial Hygiene Association Journal, 48(7), 634-638, 1987.

62. Koutrakis, P., Sioutas, C., Ferguson, S., Wolfson, J., Mulik, J. and Burton, R. : Development and evaluation of a glass honeycomb denuder/filter pack system to collect atmospheric gases and particles. Environmental Science \& Technology, 27(12), 2497-2501, 1993.

63. Poon, W., Pui, D., Lee, C. and Liu, B. : A compact porous-metal denuder for atmospheric sampling of inorganic aerosols. Journal of Aerosol Science, 25(5), 923-934, 1994.

64. Turpin, B., Liu, S., Podolske, K., Gomes, M., Eisenreich, S. and McMurry, P. : Design and evaluation of a novel diffusion separator for measuring gas/particle distributions of semivolatile organic compounds. Environmental Science \& Technology, 27(12), 2441-2449, 1993.

65. Calvert, G. M., Ward, E., Schnorr, T. M. and Fine, L. J. : Cancer risks among workers exposed to metalworking fluids: A systematic review. American Journal of Industrial Medicine, 33(3), 282-292, 1998.

66. Rosenmann, K. D., Reily, M. J., Kalinowski, D. and Watt, F. : Occupational asthma and respiratory symptoms among workers exposed to machining fluids. In Industrial Metalworking Environment, pp. 143-146, 1995.

67. Kreiss, K. and Cox-Ganser, J. : Metalworking fluidassociated hypersensitivity pneumonitis: a workshop summary. American Journal of Industrial Medicine, 32(4), 423-432, 1997.

68. Alomar, A. : Occupational skin-disease from cutting fluids. Dermatologic Clinics, 12(3), 537-546, 1994.

69. Sprince, N., Palmer, J., Popendorf, W., Thorne, P., Selim, M., Zwerling, C. and Miller, E. : Dermatitis among automobile production machine operators exposed to metal-working fluids. American Journal of Industrial Medicine, 30(4), 421-429, 1998.

70. Woskie, S., Smith, T., Hammond, S. and Hallock, M. : Factors affecting worker exposures to metalworking fluids during automotive component manufacturing. Applied Occupational and Environmental Hygiene, 9(9), 612-621, 1994.

71. Henriks-Eckerman, M., Suuronen, K., Jolanki, R., Riala, R. and Tuomi, T. : Determination of occupational exposure to alkanolamines in metal-working fluids. Annals of Occupational Hygiene, 51(2), 153-160, 2007.

72. García, A. : Occupational exposure to pesticides and congenital malformations: a review of mechanisms, methods, and results. American Journal of Industrial Medicine, 33(3), 1998.

73. Miller, G. : Sustaining the Earth. Pacific Grove, California: Thompson Learning, Inc., 2004.

74. IARC : Occupational Exposure in Insecticide
Application, and Some Pesticides. Lyon, France: International Agency for Research on Cancer, 1991.

75. US NIOSH : Method 5600 Organophosphorus Pesticides. In NIOSH Manual of Analytical Methods (NMAM), P.M. Eller and M. Cassinelli (eds.). Cincinnati, Ohio: DHHS (NIOSH) Publication 94-113, 1994.

76. US NIOSH : Method 5601 Organonitrogen Pesticides. In NIOSH Manual of Analytical Methods (NMAM), P.M. Eller and M. Cassinelli (eds.). Cincinnati, Ohio: DHHS (NIOSH) Publication 94-113, 1998.

77. US NIOSH : Method 5602 Chlorinated and Organonitrogen Herbicides (Air Sampling). In NIOSH Manual of Analytical Methods (NMAM), P.M. Eller and M. Cassinelli (eds.). Cincinnati, Ohio: DHHS (NIOSH) Publication 94-113, 1998.

78. US NIOSH : Method 5502 Aldrin. In NIOSH Manual of Analytical Methods (NMAM), P.M. Eller and M. Cassinelli (eds.). Cincinnati, Ohio: DHHS (NIOSH) Publication 94-113, 1994.

79. US NIOSH : Method 5514 Demeton. In NIOSH Manual of Analytical Methods (NMAM), P.M. Eller and M. Cassinelli (eds.). Cincinnati, Ohio: DHHS (NIOSH) Publication 94-113, 1994.

80. US EPA : Reregistration Eligibility Decision for Thiram. Washington, DC: EPA, 2004.

81. US ACGIH : TLVs and BEIs. Cincinnati: ACGIH, 2009.

82. IARC : Polychlorinated Dibenzo-para-Dioxins and Polychlorinated Dibenzofurans. Lyon, France: International Agency for Research on Cancer, 1997.

83. Jensen, T. and Hites, R. : Aromatic diesel emissions as a function of engine conditions. Analytical Chemistry, 55(4), 594-599, 1983.

84. Kagawa, J. : Health effects of diesel exhaust emissions - a mixture of air pollutants of worldwide concern. Toxicology, 181, 349-353, 2002.

85. WHO : Environmental Health Criteria 171: Diesel fuel and exhaust emissions. Geneva, Switzerland: World Health Organization, 1996.

86. US NIOSH : Health Effects of Occupational Exposure to Asphalt. United States National Institute of Occupational Safety and Health, 2000.

87. Kitto, A., Pirbazari, M., Badriyha, B., Ravindran, V., Tyner, R. and Synolakis, C. : Emissions of volatile and semi-volatile organic compounds and particulate matter from hot asphalts. Environmental Technology, 18(2), 121-138, 1997.

88. McClean, M., Rinehart, R., Ngo, L., Eisen, E., Kelsey, K. and Herrick, R. : Inhalation and dermal exposure among asphalt paving workers. Annals of Occupational Hygiene, 48(8), 663-671, 2004.

89. Nielsen, T., Jørgensen, H., Larsen, J. and Poulsen, M. : City air pollution of polycyclic aromatic hydrocarbons and other mutagens: occurrence, sources and health effects. Science of the Total Environment, 189, 41-49, 1996. 
90. Nebert, D., Jensen, N., Levitt, R. and Felton, J. : Toxic chemical depression of the bone marrow and possible aplastic anemia explainable on a genetic basis. Clinical Toxicology, 16(1), 99-122, 1980.

91. Legraverend, C., Guenthner, T. and Nebert, D. : Importance of the route of administration for genetic differences in benzo [a] pyrene-induced in utero toxicity and teratogenicity. Teratology, 29(1), 1984.

92. White, K. L. J., Lysy, H. H. and Holsapple, M. P. : Immunosuppression by polycyclic aromatic hydrocarbons: a structure-activity relationship in $\mathrm{B} 6 \mathrm{C} 3 \mathrm{~F} 1$ and DBA/2 mice. Immunopharmacology, 9(3), 155164, 1985.

93. Bergman, T. A., Johnson, D. L., Boatright, D. T., Smallwood, K. G. and Rando, R. J. : Occupational exposure of nonsmoking nightclub musicians to environmental tobacco smoke. American Industrial
Hygiene Association Journal, 57(8), 746-752, 1996.

94. Aviado, D. M. : Cardiovascular disease and occupational exposure to environmental tobacco smoke. American Industrial Hygiene Association Journal, 57(3), 285-294, 1996.

95. Scherer, G., Conze, C., Tricker, A. R. and Adlkofer, F. : Uptake of tobacco smoke constituents on exposure to environmental tobacco smoke (ETS). Journal of Clinical Investigation, 70(3-4), 352-367, 1992.

96. Scherer, G., Conze, C., von Meyerinck, L., Sorsa, M. and Adlkofer, F. : Importance of exposure to gaseous and particulate phase components of tobacco smoke in active and passive smokers. International Archives of Occupational and Environmental Health, 62(6), 459-466, 1990. 